\title{
Abrasion Properties of Some Building Stone Wastes and Usability for Sustainability
}

\author{
Bilgehan Kekec*, Niyazi Bilim and Sertac Dündar \\ Department of Mining Engineering, Selcuk University, Konya, Turkey
}

\begin{abstract}
Knowledge of the abrasion resistance of aggregates is important when using them for asphalt and concrete mixes and highway construction materials. In this study, the usability of natural building stone waste as aggregates for different engineering applications was investigated. To this end, test samples were obtained from a number of natural stone quarries and stone cutting factories. The abrasion tests were carried out on the test samples and results were compared between samples. The abrasion strength values were determined with both the Micro-Deval (MDe) and the Los Angeles (LA) abrasion test methods. A correlation coefficient was also determined between the LA and MDe tests results using an appropriate statistical model.
\end{abstract}

Keywords: Los Angeles abrasion test, Micro-Deval abrasion test, building stone, waste management

\section{Introduction}

The rapid consumption of natural resources has led researchers to work on the efficient utilization of such resources. To this end one can convert waste into useful raw materials, or determine alternative uses of the industrial waste materials. This has become increasingly important as storing or dumping waste may result in environmental problems. In addition, the use of industrial waste in a different application of the construction industry prevents rapid consumption of limited natural resources and can mitigate environmental problems related to raw material production,

Industrial waste such as blast furnace slag, fly ash, building demolition material, marble waste and dismantled asphalt have been used as highway and concrete materials (Ahmed 1993, Ramaswamy and Aziz 1992, Schroeder 1994, Ceylan and Manca 2013, Holtz and Eighmy 2000, Hebhoub et al 2011). It is very important to analyze whether these aggregates are of the required quality in terms of their application and their economic life. This analysis can be carried out using various tests such as the Micro-Deval and the Los Angeles abrasion tests, sieve analysis, durability chemical resistance, peeling and adhesion, and freezingthawing tests (Erdem et al 1996). Specifications for aggregates also include terms that define the grain shape, cleanliness and surface textures.

The abrasion test is one of the more important tests that are applied to determine aggregate quality. Having a good abrasion resistance is particularly important for concrete and asphalts mixes that are exposed to abrasion.

Ninety five percent of the materials used for asphalt roads on average consist of aggregates (Akbulut and Gürer 2006). Bituminous binders in the asphalt exhibit plastic behavior and are sensitive to changes in temperature. Thus, the stability or deformation resistance of the covering largely depends on the interlocking of mineral aggregates.

According to the General Directorate of Highways specifications, the materials used for the foundation layer should have a maximum of $40 \%$ of abrasion loss. The maximum loss for the abrasion layer should be $30 \%$.

In the last 20-25 years, industrial waste has rapidly increased and waste disposal methods have become very costly; this contributed to an increase in the recycling of such waste in various manufacturing processes (Y1lmaz and Sütaş 2006).

In this study, we determined the abrasion resistance of natural stone waste through the Micro-Deval and Los Angeles abrasion tests. Also, their suitability and sustainability for use as aggregates in road construction and concrete mixes were studied.

\section{Materials and Methods}

This section explains the materials and methods used in the study and the test procedures used in this research. Natural building stones that can be used to produce aggregates belong to three categories as explained below.

\subsection{Magmatic natural building stones}

Magmatic natural stones are formed from the magma rising to the crust. Magmatic natural building stones are harder and have a higher strength than sedimentary rocks. Magmatic natural stones can be categorized as deep rocks, surface rocks and dykes. In addition to granite, rocks such as syenite, diorite, gabbro, peridotite, ophicalcite, monzonite, dunite, harzburgite, lherzolite, labradorite, granodiorite, quartz porphyry, basalt, andesite, trachyte and diabase are also placed in this category.

* Corresponding Author: B. Kekeç, kekec@ selcuk.edu.tr, phone: +90 544-544-5842

Copyright @ 2017 Canamaple Academia Services, http://press.camdemia.ca

DOI: $10.15273 /$ gree.2017.02.039 


\subsection{Metamorphic natural building stones}

Metamorphic natural building stones are formed by mineralogical and textural transformation as a result of changing pressure and heat conditions of the sedimentary and magmatic natural building stones while in solid form. Marble, which is significant for the natural stone industry is formed by transformation of calcitic limestone and dolomitic limestone. Rocks such as marble, gneiss, amphibolite, schist, phyllite and eclogite are placed in this category.

\subsection{Sedimentary natural building stones}

Sedimentary natural building stones can be classified under two groups as detritic or calcite natural building stones and chemical sedimentary natural building stones. Examples for this category include onyx, travertine, conglomerate, breccia, slate, greywacke.

\subsection{Micro-Deval abrasion test Device and Procedure}

The Micro-Deval test device should consist of a maximum of 5 drums with an internal dimension of $154 \pm 1 \mathrm{~mm}$ between the floor and the inner surface of the cap. The drums are used with a special device made of stainless steel and attached to two axles rotating in the horizontal direction with a thickness of at least $3 \mathrm{~mm}$ (Figure 1) The abrasive material consists of steel balls with diameters of $10 \pm 0.59$ mm (ASTM D7428).

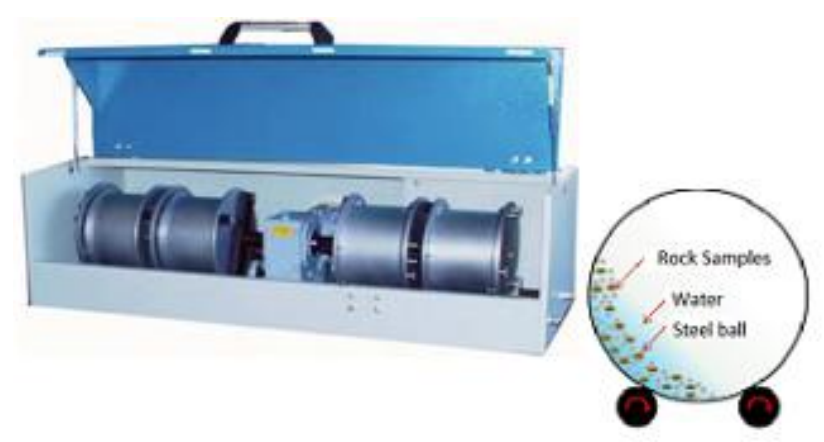

Figure 1. Micro-Deval abrasion test device.

Each sample is placed inside a drum, and abrasive steel balls and $2.5 \pm 0.05 \mathrm{~L}$ water is added to each drum to obtain a load of $5000 \pm 2 \mathrm{~g}$. After the drums are rotated $12000 \pm 10$ times at $100 \pm 5$ rotations/min the experiment is concluded. At the end of the experiment, the drum's caps are removed and the interior cap is carefully washed, and the washed material is collected. All the materials and washing waters are placed on a $1.6 \mathrm{~mm}$ sieve, which is protected with a protective $8 \mathrm{~mm}$ sieve, and then washed with clean water. The steel balls are separated from the aggregate with a magnet, ensuring that any loss of grains is avoided, and the remaining material is dried again on a $1.6 \mathrm{~mm}$ sieve. After the materials are dried in the drying oven, the mass of the aggregate is measured at the end of the test, and the MicroDeval coefficient is calculated using the following equation:

Mde $=(500-m) / 5$ where Mde is Micro-Deval Coefficient, $\%$; $\mathbf{m}$ is the mass of the fraction that remains on the $1.6 \mathrm{~mm}$ sieve, $\mathrm{g}$.

\subsection{Los Angeles abrasion test device and procedure}

The aim of the "Los Angeles abrasion test" or a LA test is to determine the abrasiveness of aggregates by rotation of a drum, where aggregates and standard steel balls are mixed in together for a specific number of rotations. The percentage wear of aggregates due to rubbing with steel balls is determined as the Los Angeles Abrasion value.

The Los Angeles test device is a special device in which $5000 \mathrm{~g}$ of the sample and the steel ball load are placed. The drum rotates 500 times with a constant speed of 31-33 rotations per minute (Figure 2). The abrasive material consists of 11 spherical steel balls with a total weight of 400-445 $\mathrm{g}$ and 45-49 $\mathrm{mm}$ in diameter (ASTM C 131).

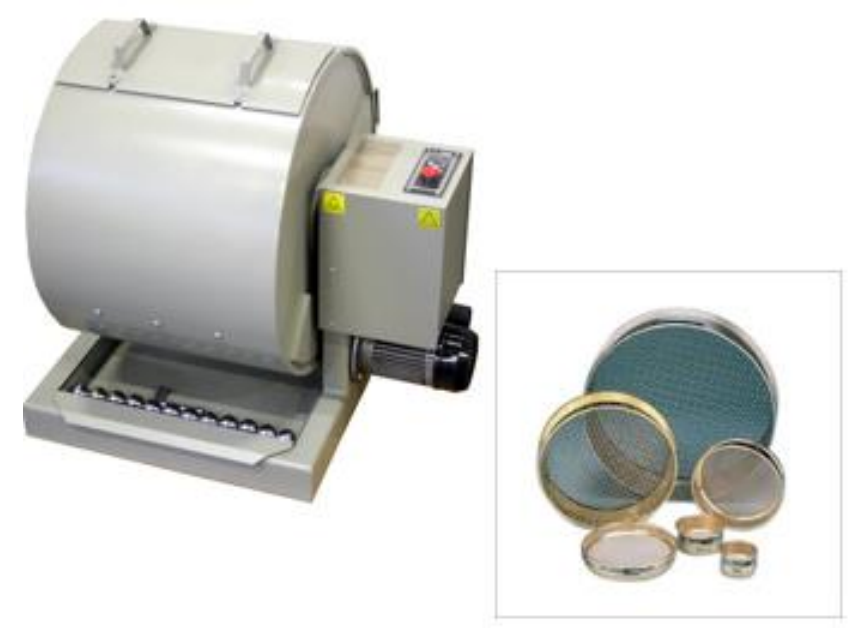

Figure 2. Los Angeles abrasion test device and sieve set.

At the end of the experiment, the cap of the device is opened and the tested sample is transferred to the device's tray. Afterwards the steel balls are removed from the sample. The sample that remains on a $1.6 \mathrm{~mm}$ sieve is washed and dried. Finally, the dried sample is weighed and the Los Angeles abrasion value, LA is calculated using the following equation:

\section{$\mathbf{L A}=(\mathbf{5 0 0 0}-\mathbf{m}) / \mathbf{5 0}$}

where LA is Los Angeles coefficient, \%; $\mathbf{m}$ is the mass of the fraction that remains on the $1.6 \mathrm{~mm}$ sieve, $\mathrm{g}$.

\subsection{Preparation of the samples}

In this study, waste material from six different natural building stones which are produced in various regions of Turkey are investigated. Specific grain size aggregate samples were collected from these rock types and abrasion tests were conducted.

The results obtained from this study will be used as guidelines for road construction and concrete production whenever these particular aggregates are used. In addition, the LA and MDe values can be correlated with each other. The values obtained from these tests are very important to 
ensure that such the building stone waste can be used by the aggregate industry. The experimental study has 5 steps.

Crushing: The large sized waste materials are reduced to aggregate size using a lab-type jaw crusher (Figure 3). The material size selected for the study is $10-14 \mathrm{~mm}$, the material was gradually reduced by repeatedly crushing and sieving the sample, starting with a jaw opening of $20 \mathrm{~mm}$ (Figure 3). Thus, the required aggregate size was obtained with less material.

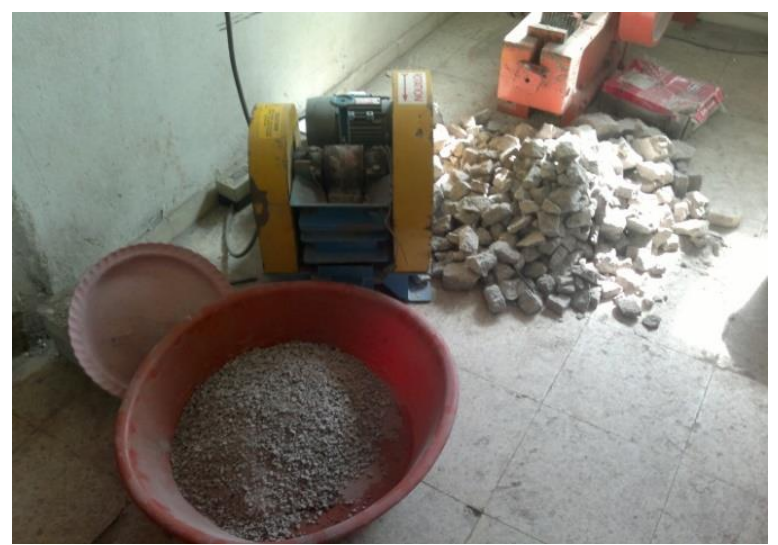

Figure 3. Lab-type jaw crusher.

Sieving: The aggregate crushed with the jaw crusher was sieved using standard sieves and classified in the 10-14 mm range, which is required for the experiments (Figure 4).

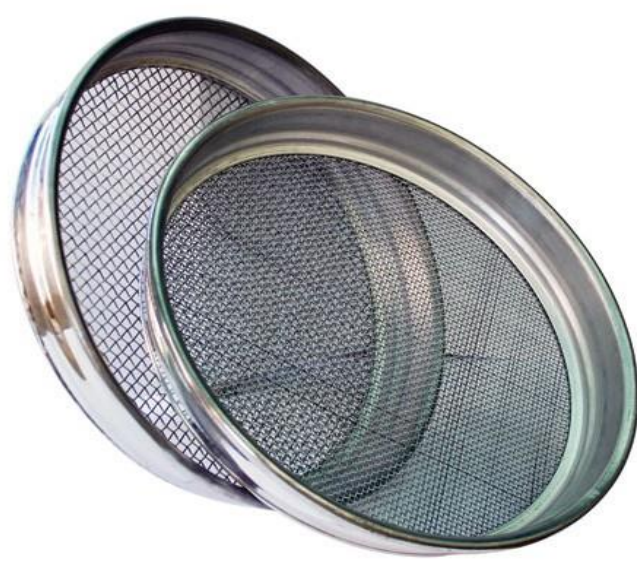

Figure 4. Standard sieves.

Washing: The samples used in the abrasion test were washed in accordance with the respective standards (Figure $5)$.

Drying: The samples were placed inside an oven at $110^{\circ} \mathrm{C}$, and they were kept at a constant temperature for 24 hours (Figure 6).

Weighing: After the drying process, the samples were placed inside sample bags, and were prepared for the experiments by being separately weighed for $5000 \mathrm{~g}$ (for the LA value) and $500 \mathrm{~g}$ (for the MDe value).

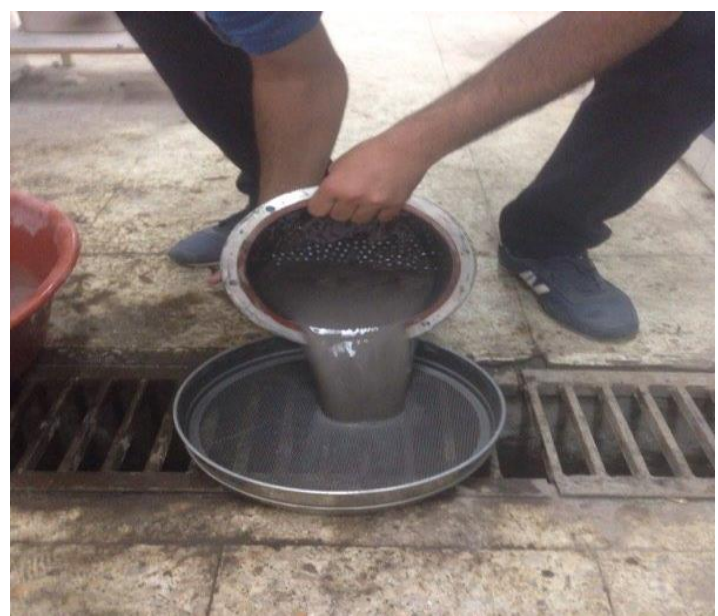

Figure 5. Washed samples.

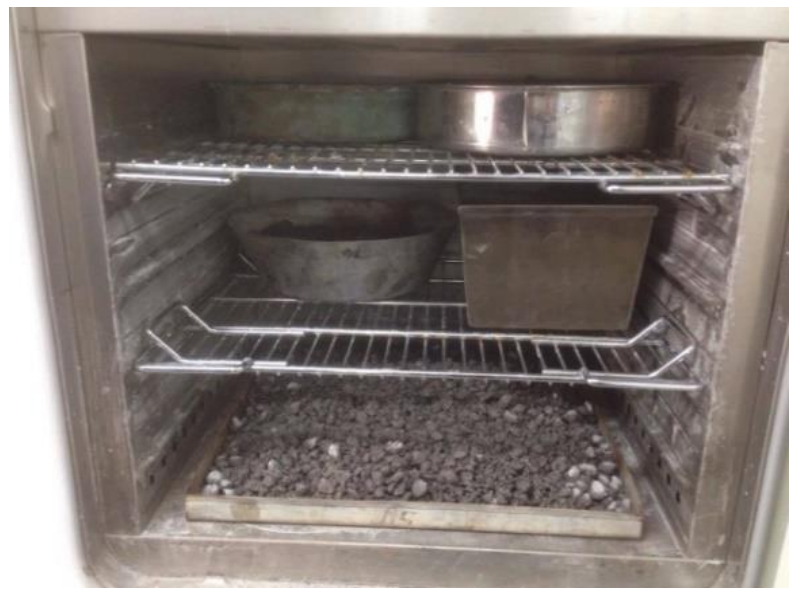

Figure 6. The samples inside the drying oven.

\section{Experimental Study and Evaluation}

The petrographic features of the test samples were analyzed with a petrography microscope and their detailed evaluations are given in Table 1.

The test samples were prepared in accordance with the relative standards and then the Los Angeles and MicroDeval abrasion tests were conducted. Abrasion values and calculated values for these samples are shown in Tables 2 and 3 .

The values in Tables 2 and 3 indicate that the Basalt- $\mathrm{N}$, Basalt-K and Granite-AG samples had the lowest abrasion coefficients in both tests. The metamorphic marble sample lost more than $50 \%$ of weight at the end of the Los Angeles abrasion test.

Examination of the Micro-Deval abrasion coefficients reveals that the loss value appears to be lower than $50 \%$. The Dacite-S rock was determined to be the sample with the lowest abrasion resistance. 
Table 1. Mineralogical content of test samples (Kekeç et al 2009, Comaklı et al 2011).

\begin{tabular}{ll}
\hline Rock Types & Mineralogical contents \\
\hline \multirow{2}{*}{ Basalt-N } & $\begin{array}{l}\text { Quartz (15\%), Plagioclase (20\%), } \\
\text { Amphibole (11\%), Biotite (5\%), } \\
\text { Opaque (4\%), }\end{array}$ \\
\hline \multirow{2}{*}{ Pacite-S } & $\begin{array}{l}\text { Plagioclase (35\%), Amphibole (8\%), } \\
\text { Biotite (12\%), Quartz (10\%), Volcanic } \\
\text { glass (35\%) }\end{array}$ \\
\hline & $\begin{array}{l}\text { Quartz (29\%), Plagioclase (31.5\%), } \\
\text { Orthoclase (21\%), Amphibole (1.5\%), } \\
\text { Biotite (7\%), Opaque (3\%), Epidote } \\
\text { (3\%), Muscovite (1.5\%), Apatite } \\
(1.5 \%), \text { Sericite (1\%) }\end{array}$ \\
\hline Marble-M & $\begin{array}{l}\text { Skeletal grains (38\%) Micrite (60\%), } \\
\text { (Opaque 2\%) }\end{array}$ \\
\hline Marble-Y & Dolomite (100\%) \\
Basalt-K & $\begin{array}{l}\text { Plagioclase Microlites (76\%), Olivine } \\
\text { (15\%), Clinopyroxene (8\%), Opaque } \\
\text { minerals (1\%) }\end{array}$ \\
\hline
\end{tabular}

Table 2. Los Angeles abrasion test values.

\begin{tabular}{l|lll}
\hline \multirow{2}{*}{ Sample Name } & \multicolumn{3}{l}{ Los Angeles Experiment } \\
\cline { 2 - 4 } & $\begin{array}{l}\text { First } \\
\text { weighing } \\
(\mathbf{g})\end{array}$ & $\begin{array}{l}\text { Last } \\
\text { weighing } \\
(\mathbf{g})\end{array}$ & $\begin{array}{l}\text { \% } \\
\text { LA }\end{array}$ \\
\hline Basalt-N & 5000.9 & 4430.5 & 11.41 \\
\hline Dacite-S & 5000.2 & 1207.9 & 75.85 \\
\hline Granite-AG & 5000.3 & 3852.0 & 22.97 \\
\hline Marble-M & 5000.1 & 1717.7 & 65.65 \\
\hline Marble-Y & 5000.5 & 1902.8 & 61.96 \\
\hline Basalt-K & 5000.1 & 3144.5 & 37.11 \\
\hline
\end{tabular}

Table 3. Micro Deval abrasion test values.

\begin{tabular}{l|ccc}
\hline \multirow{2}{*}{ Sample Name } & \multicolumn{3}{|c}{ Micro Deval Experiment } \\
\cline { 2 - 4 } & $\begin{array}{c}\text { First } \\
\text { weighing }\end{array}$ & $\begin{array}{c}\text { Last } \\
\text { weighing }\end{array}$ & $\begin{array}{c}\text { \% } \\
\text { MDe }\end{array}$ \\
\hline Basalt-N & 500.2 & 461.39 & 7.76 \\
\hline Dacite-S & 500.1 & 213.31 & 57.36 \\
\hline Granite-AG & 500.3 & 423.2 & 15.42 \\
\hline Marble-M & 500.1 & 339.4 & 32.14 \\
\hline Marble-Y & 500.4 & 360.2 & 28.04 \\
\hline Basalt-K & 500.0 & 431.0 & 13.80 \\
\hline
\end{tabular}

To define relationship among these abrasion tests (LA and MDe), a relation was developed as shown in Figure 7. The correlation coefficient calculate for this relationship is $\mathrm{R}^{2}=0.9197$. The later indicates that strong correlation exists between the values obtained by the LA and MDe tests.

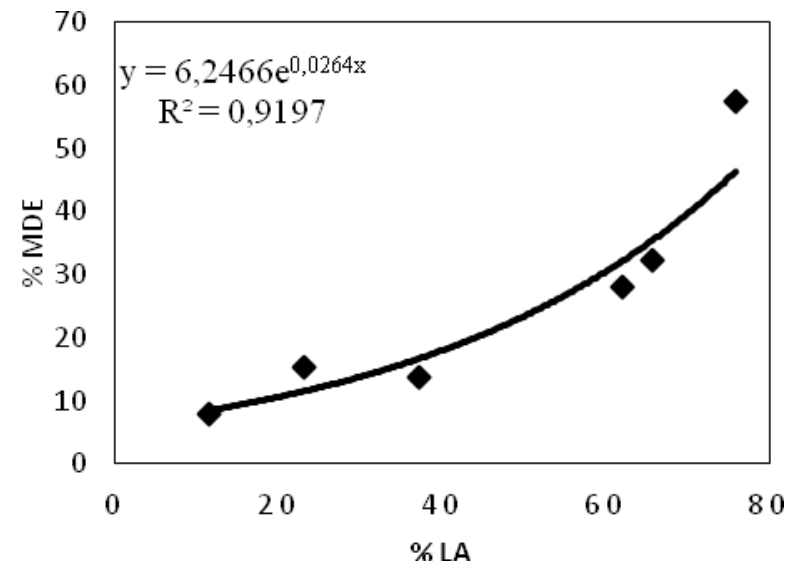

Figure 7. The relation graph between LA and MDe.

\section{Results}

A decrease of abrasion resistance in aggregates would cause premature degradation, early loss of skid resistance, dust pollution and other issues. Turkey has various natural building stone resources in terms of reserves, production capabilities and quality. It is very important to recycle waste materials that arise during production and processing of natural stones, and return them to the economy. An investigation was performed on six different natural stones produced in Turkey.

According to abrasion test results, the Basalt-K, Basalt$\mathrm{N}$ and Granite-AG samples showed the highest resistance to abrasion. According to the data obtained from these samples, they may be used in regions where the climate conditions are hard and variable, where traffic is heavy and abrasive factors are numerous. Furthermore, these rocks may also be used as concrete aggregate and road filler as necessary.

The other two metamorphic marble samples that were tested, Marble-M and Marble-Y may not be suitable for use in highly abrasive areas due to the abrasion coefficients that were determined. However, these may be used as filling material or in concrete mixes.

According to the results of the present abrasion study, Dacite-S has the least resistant to abrasion. Thus, it is not suitable to use Dacite-S in asphalt mixes or as a concrete aggregate. However, it may be used as filler material.

Finally the LA and MDe abrasion values show a string correlation as indicated by a very high correlation coefficient of $\mathrm{R}^{2}=0.9197$.

\section{References}

Ahmed, I., 1993. Use of waste materials in highway construction. Noyes Data Corporation, Park Ridge, USA, 125p.

Akbulut, H. and C. Gürer, 2006. Use of waste marble as aggregate in asphalt pavement. IMO Technical Journal, 17(4): 3943 - 3960. (in Turkish)

ASTM C131, 2006. Standard test method for resistance to degradation of small-size coarse aggregate by abrasion 
and impact in the Los Angeles machine. DOI: 10.1520/C0131_C0131M-14.

ASTM D7428, 2015. Standard test method for resistance of fine aggregate to degradation by Abrasion in the micro-deval apparatus. DOI: 10.1520/D7428-15.

Ceylan, H. and S. Manca, 2013. Evaluation of concrete aggregate marble pieces. SDU Journal of Technical Sciences, (3): 21 - 25.

Comaklı, R., N. Bilim, S. Kahraman, A.E. Dursun and B. Kekeç, 2011. Investigation of the relations between the cerchar abrasivity index and percentage of the abrasive minerals for volcanic rocks. Proceedings of the Twentieth International Symposium on Mine Planning and Equipment Selection MPES 2011, Almaty, Republic of Kazakhstan, 826 - 834.

Erdem, F., A.B. Yener, Z. Ozgoren and A. Turabik, 1996. Usability of the natural and crushed aggregates as building materials which are supplied from the quarries and sand-gravel pits in sivas and its surrounding. I. National Aggregate Symposium' 96, İstanbul, 325 - 332. (in Turkish)
Hebhoub, H., H. Aoun, M. Belachia, H. Houari and E. Ghorbel, 2011. Use of waste marble aggregates in concrete. Construction and Building Materials, 25(3): 1167 - 1171.

Holtz, K. and Eighmy T., 2000. Scanning European advances in the use of recycled materials in highway construction. Scanning Trip Summary Report, USA, 64(1): $34-40$.

Kekeç, B. and M.K. Gokay, 2009. Mechanical properties of erciyes mountain volcanics and their usability as dimensional building Stone. SGEM 2009, Albena, Bulgaria, (1): 441 - 448.

Ramaswamy, S. D. and M. A. Aziz, 1992. Some waste materials in road construction. Utilization of Waste Materials in Civil Engineering Construction. American Society of Civil Engineers, New York, NY, pp. 153 165.

Schroeder, R.L., 1994. The use of recycled materials in highway construction. Public Roads, 58(2): 32 - 41.

Yılmaz, A. and İ. Sütaş, 2008. Use of ferrochromium slag as highway base material. IMO Technical Journal, 19(3): $4455 \quad$ - $4470 . \quad$ (in $\quad$ Turkish) 